\title{
CANTERAS, CUEVAS, ACUEDUCTOSY CAMINOS CONECTADOS A LA METRÓPOLI WARI
}

\author{
ISMAEL PÉREZ CALDERON ${ }^{1}$ \\ Universidad NACIONAL SAN CRISTÓbaL DE HUAMANGA \\ zismaelunsch@hotmail.com \\ JOSÉ AMORÍN ${ }^{2}$ \\ Ministerio de CULTURA - AYACUCHO \\ joseamoringaribay@hotmail.com
}

\section{RESUMEN}

El objetivo primordial de la presente investigación es dar a conocer que siguiendo en los términos de la arqueología del paisaje se ha realizado en reconocimiento directo, complementado con el mapeo empleadas en la exploración arqueológica y fuentes etnográficas, llegándose a registrar por el momento 34 estructuras arqueológicas entre canteras, cuevas, acueductos y caminos conectados a la metrópoli Wari, indicadores que sirven para tener un mayor acercamiento y entendimiento del manejo del territorio en la capital imperial, funcionamiento y relación con asentamientos periféricos, modo de vida de los pobladores, actividades agrícolas, artesanales, ceremoniales, incluyendo construcción de la enigmática ciudad de piedra e ideología expresado en el culto a las cuevas, cerros, manantiales y lagunas donde moran los wamanis o espíritus de la cosmovisión andina.

Palabras clave: Wari, cuevas, acueductos, caminos.

\section{SUMMARY}

The primary objective of the present research is a description which means in the terms of landscape archeology is done in the direct recognition, complemented with the mapping used in archaeological exploration and sources and sources, arriving at a recorder for the moment 34 archaeological structures Among quarries, caves, aqueducts and roads connected to the Wari metropolis, the indicators that serve to have a main approach and the understanding of the management of the territory in the imperial capital, operation and relation with the peripheral settlements, way of life of The inhabitants, Craft, ceremonial, including the construction of the enigmatic city of stone and the ideology expressed in the cult of the caves, hills, springs and lagoons where the Wamanis or spirits of the Andean cosmovision dwell.

KeYwoRds: Wari, caves, aqueducts, roads.

1. Profesor de la especialidad de Arqueología en la Universidad Nacional de San Cristóbal de Huamanga

2. Arqlo. De la Dirección Desconcentrada de Cultura, Ayacucho-Ministerio de Cultura 


\section{INTRODUCCIÓN}

Wari, considerada como la capital política y administrativa de uno de los estados prehispánicos más poderosos y grandes que se gestó en Ayacucho siglos antes de los incas y 3500 años después de Caral, que se expandió por casi todo el territorio peruano, requiere de un mayor estudio que incluya no solo los servicios urbanísticos que ofrecía la ciudad sino también de los restos de relación cultural asociados con obras de infraestructura que fueron planificadas y ejecutadas por el Estado Wari a través de las autoridades residentes en la misma ciudad con participación de una numerosa población establecida en el área periférica (Fig. 1 y 1 a ).

Al inicio, el trabajo estuvo abocado a buscar mayor bibliografía incluyendo fuentes documentales que dan a conocer de la zona de Wari como partes de haciendas, importancia de caminos de interrelación entre Ayacucho y valles colindantes, presencia de canteras de arcilla, piedras y otros materiales empleados en la construcción de la ciudad y actividades artesanales y sobre los mitos y leyendas de algunos lugares sagrados como las cuevas y abrigos rocosos, cerros, etc. Por tal razón en esta ocasión exponemos los resultados de la recolección de datos, organización y procesamiento de los materiales arqueológicos fundamentalmente cerámica y artefactos líticos que forman parte de un conjunto de instrumentos y objetos utilizados por los asentamientos prehispánicos ubicados cerca de las canteras, cuevas, acueductos y caminos.

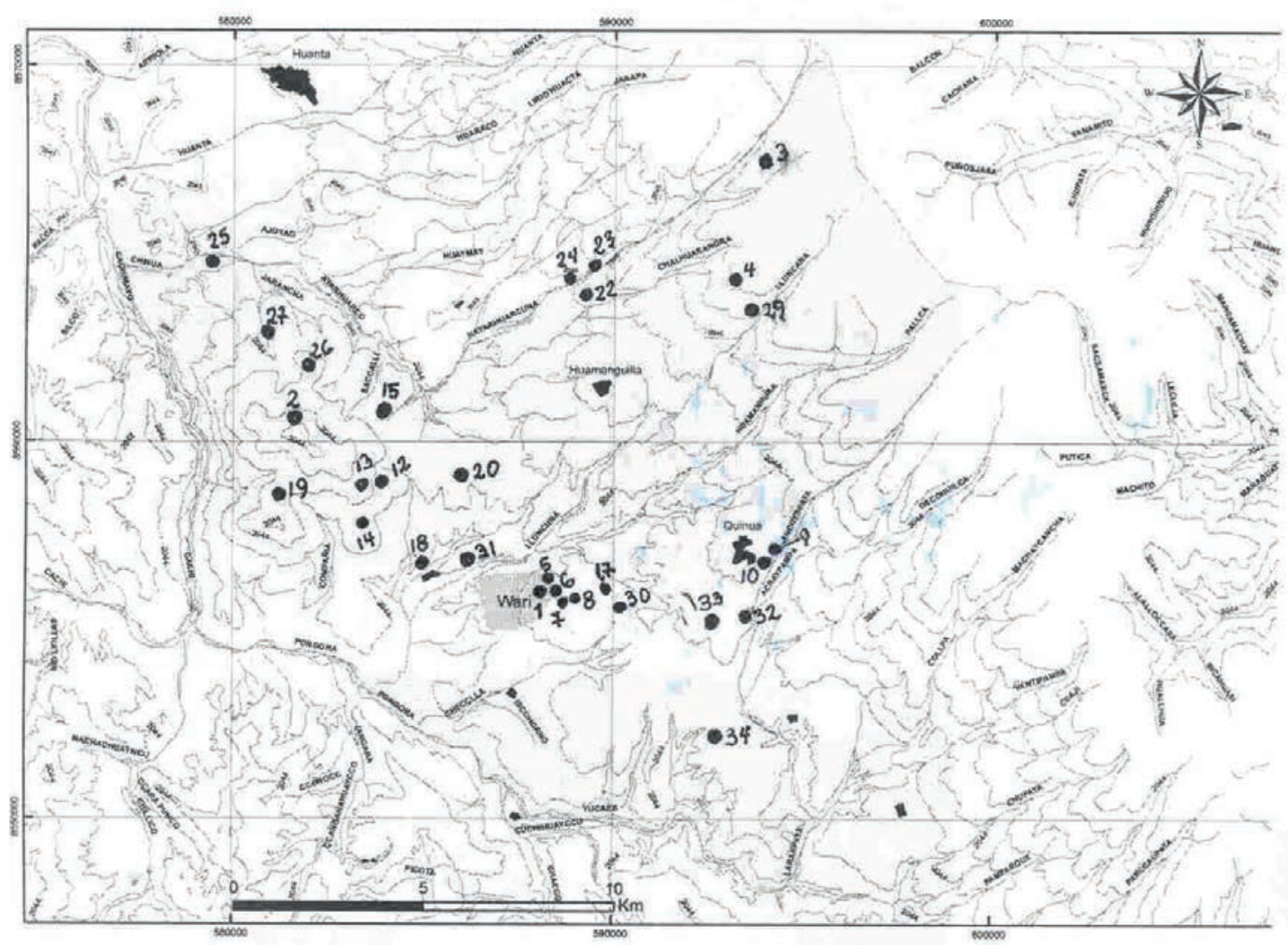

Fig. 1. Ubicación de las canteras, cuevas, acueductos y caminos. 


\begin{tabular}{|c|c|c|c|c|c|}
\hline № & Sitio & Altura & Coordenadas utm & Estructura arqueológica & Época (s) \\
\hline 1 & San Cristóbal & 2825 & & Cantera & I.W \\
\hline 2 & J aywacanche & 2900 & $8562400 \mathrm{~N} / 584300 \mathrm{E}$ & Cantera & I.W \\
\hline 3 & Yanaqocha & 4100 & $8567100 \mathrm{~N} / 594700 \mathrm{E}$ & Cantera & I.W \\
\hline 4 & Curiorgo & 4250 & $8561100 \mathrm{~N} / 598700 \mathrm{E}$ & Cantera & I.W \\
\hline 5 & Wallpaqasa & 3840 & $8555700 \mathrm{~N} / 588300 \mathrm{E}$ & Cuevas, petroglifos & I.W \\
\hline 6 & Ayamonte & 2845 & $8555400 \mathrm{~N} / 588100 \mathrm{E}$ & Muros, cantera y petroglifos & \\
\hline 7 & Zapallogasa & 3850 & $8555300 \mathrm{~N} / 588200 \mathrm{E}$ & Cantera, pocitos & I.W \\
\hline 8 & Torresmogo & 3770 & $8555200 \mathrm{~N} / 588500 \mathrm{E}$ & Petroglifos, pocitos, canaletas & I.W \\
\hline 9 & Nueva Esperanza & 3300 & $8559100 \mathrm{~N} / 595500 \mathrm{E}$ & Cantera & I.W \\
\hline 10 & Suyuhuasi Huayco & 3100 & $8559000 \mathrm{~N} / 595300 \mathrm{E}$ & Cantera & I.W \\
\hline 11 & Checclla huayco & 2650 & $8553700 \mathrm{~N} / 587300 \mathrm{E}$ & Canteras & I.W \\
\hline 12 & Pikimachay & 2990 & 8558798N/583960E & Cueva & L-ER \\
\hline 13 & Uchuypikimachay & 3050 & $8559000 \mathrm{~N} / 583000 \mathrm{E}$ & Cueva & $\mathrm{L}$ \\
\hline 14 & Ayamachay & 2900 & $8558500 \mathrm{~N} / 583900 \mathrm{E}$ & Cueva & L \\
\hline 15 & Rosamachay & 2877 & $8561900 \mathrm{~N} / 584700$ & Cueva & F-I.W \\
\hline 16 & Ruyru Rumi & 4100 & $8562500 \mathrm{~N} / 597800 \mathrm{E}$ & Cuevas y abrigos rocosos & LTD \\
\hline 17 & Pampachacra & 2900 & $8556200 \mathrm{~N} / 590100 \mathrm{E}$ & Acueducto & I.W \\
\hline 18 & Tablapampa & 2850 & $8558200 \mathrm{~N} / 585700 \mathrm{E}$ & Estructura Cercada & I.W \\
\hline 19 & Huaynahuillca & 3150 & $8558700 \mathrm{~N} / 581200 \mathrm{E}$ & Camino & I.W \\
\hline 20 & La Vega & 2980 & $8560050 \mathrm{~N} / 587050 \mathrm{E}$ & Camino & I.W \\
\hline 21 & Chalhuarangra & 3624 & $8564449 \mathrm{~N} / 591540 \mathrm{E}$ & Camino/canal & I.W \\
\hline 22 & Ayahuarcuna & 3164 & $8563041 \mathrm{~N} / 587906 \mathrm{E}$ & Camino Prehispánico & I.T \\
\hline 23 & Ayahuarcuna & 2927 & $8561700 \mathrm{~N} / 586000$ & Camino Prehispánico & $\mathrm{F}$ \\
\hline 24 & Ayahuarcuna & 2927 & $8561800 \mathrm{~N} / 585500$ & Puente & Colonial \\
\hline 25 & Chiwa & 2500 & $8563400 \mathrm{~N} / 583200$ & Camino Prehispánico & I.W-IT \\
\hline 26 & Allcohillca & 3020 & $8561900 \mathrm{~N} / 581900$ & Camino Prehispánico & F-IW \\
\hline 27 & Chiwa & 2720 & $8563700 \mathrm{~N} / 581100 \mathrm{E}$ & Camino & I.W \\
\hline 28 & Condormarca & 3900 & $8564700 \mathrm{~N} / 594500 \mathrm{E}$ & Camino Prehispánico & I.W \\
\hline 29 & Condorcunca & 3750 & $8559700 \mathrm{~N} / 595900 \mathrm{E}$ & Camino Prehispánico & I.W \\
\hline 30 & Ramospata & 3850 & $8556100 \mathrm{~N} / 589100 \mathrm{E}$ & Camino & I.W \\
\hline 31 & Putica & 2650 & $8558700 \mathrm{~N} / 588900 \mathrm{E}$ & Camino, terrazas & I.W \\
\hline 32 & Yacutinco & 2700 & $8554800 \mathrm{~N} / 593400 \mathrm{E}$ & Camino & I.W \\
\hline 33 & Patasuyoc & 3100 & $8554000 \mathrm{~N} / 593100 \mathrm{E}$ & Camino & I.W \\
\hline 34 & Chullcamogo & 2800 & $8551400 \mathrm{~N} 594200 \mathrm{E}$ & Camino & I.W \\
\hline
\end{tabular}

Fig. 1 a. Cuadro con distribución de Canteras, cuevas, acueductos y caminos de la metrópoli Wari, (Pérez 2009).

La investigación consistió efectuar el estudio de obras prehispánicas de infraestructura social y económica (canteras, caminos y acueductos), a fin de proponer a los organismos pertinentes medidas de conservación, protección, acondicionamiento y puesta en valor, así como desarrollar estrategias de intervención, ante la alteración de los restos por la ejecución de carreteras, expansión de fronteras agrícolas, etc., de igual forma realizar un reconocimiento sistemático, con mapeo en los alrededores del complejo Wari, para luego profundizar la investigación con proyectos interdisciplinarios que incluyan excavaciones y análisis de suelos, estudios de palinología, etc.

\section{Antecedentes}

Fowller (1923) en la obra Monografía y descripción de Ayacucho hace alusión de una serie de caminos que interconectan al valle de Huarpa -donde se encuentra las ciudades y capitales de los estados prehispánicos de Wari y Ñawimpuquio- con la selva del río Apurímac, cruzando las cumbres de Pacerin, Pucaccasa, Canrao-Ccasa, Tircos, abra de Husmay, Culloccasa, Tocto en la cordillera del Rasuwillca donde sin duda una de las rutas de mayor tránsito fue la cuenca del río Torobamba, espacio que conserva los restos del administrativo de Inkaraqay, registrado y excavado por Isbell (1972) y otros monumentos de las épocas Huarpa y Wari documentada en los últimos por Ochatoma (2011), Valdez (2009), Gagliardi (2013) y Pérez y Carrera (2016). 
En junio de 1942 Julio C. Tello es el primero que explora científicamente la cueva del infiernillo menciona haber ingresado a sus entrañas donde encontró un asta de venado asociado a lo más más profundo de la cueva lo que le conlleva a sostener que se trataba de un instrumento para extraer la arcilla que existe en el lugar y que los antiguos alfareros debieron de utilizarlo como temperante. Esta misma cueva y el cerro San Cristóbal fue explorada también por Flores.

Luis Cavero (1953), hace referencia de diferentes caminos antiguos que unen Ayacucho y Huanta con el valle del río Apurímac, cruzando la cordillera del Rasuwillca, donde existen restos de antiguas poblaciones que estuvieron integrados a la red del Estado imperial Wari, estas redes de comunicación continuaron siendo usadas en las épocas incaica, colonial y república para el comercio de productos altoandinos con productos de origen microtérmico, donde el truque o intercambio juega un rol importante por cuanto esta relacionado con diversos centros poblaciones establecidos en los territorios de los valles del Huarpa, Pampas, Mantaro y Apurímac.

Rodolfo Salazar (1936), da a conocer el interés de las poblaciones actuales establecidas en las inmediaciones del complejo Wari, para mejorar y rehabilitar antiguos canales de riego como una forma de contribuir al desarrollo de la economía de la región, lo cual motiva efectuar nuevas salidas de campo para identificar los restos de canales y antiguos reservorios que abastecieron de agua a la metrópoli Wari.

Néstor Cabrera (1955) informa sobre una leyenda y mitos referidos a la construcción de un canal (Wariperqa) empedrado que tiene como fuente a la laguna Yanacocha en las alturas de Huamanguilla, así como del acueducto de Pampachacra en el lado este del mismo complejo Wari, indica que estas obras fueron hechos por los Wari, por lo que requiere de un mayor análisis con salidas o trabajos de reconocimiento.

Lumbreras (1975), es quien brinda la información científica más precisa referente a las canteras, canales, reservorios y caminos de la metrópoli Wari, cuya información requiere también de visitas o salidas de campo orientadas a efectuar ciertas mediciones y buscar los restos asociados a fin de argumentar la presencia de grandes obras como parte proyectos vinculados con el funcionamiento de la ciudad.

Valdez y Valdez (1998) dan a conocer el rol del Estado Wari con relación a las obras de infraestructura social y económica, alcanzando referencias restos de caminos que conectaban a la ciudad Wari con pueblos aledaños. Por otro lado Pérez (1999, 2005 y 2009), informa del registro de diferentes tramos de infraestructura vial, así como de cuevas, mampuestos y canteras de piedra, arcilla y otros materiales utilizados en la construcción de la ciudad y otras obras de ingeniería civil

\section{Metodología Y TÉCNICAS}

La recuperación de datos incluyen la puesta en práctica de un conjunto de técnicas, materiales e instrumentos de trabajo necesarios para la documentación de sitios y restos culturales asociados, se ha utilizado GPS y carta nacional digitalizada, fotografías aéreas del año 1962, fichas impresas para el registro escrito de las evidencias, entrevistas, testimonios, fotografías y datos de archivo que dan cuenta del nombre de Wari desde por la segunda mitad del siglo XVIII.

Dentro de los materiales culturales asociados se ha registrado artefactos y desechos de talla lítica, arcillas y algunos fragmentos de cerámica diagnóstica que ha facilitado determinar la cronología relativa, por eso ahora estamos en condiciones de afirmar que los caminos pertenecen a la época Wari, algunas de las canteras fundamentalmente las ubicadas en Pacaycasa fueron aprovechadas desde el 
período Formativo y las cuevas fueron ocupadas desde el precerámico tal como señalan los datos de carbono 14 de materiales `procedentes de las cuevas de Pikimachay, Ayamachay y Rosamachay. Toda esta clase de información ha sido procesada y forman parte de la base de datos del complejo arqueológico Wari. El presente informe ha sido elaborado con la finalidad de dar a conocer la riqueza cultural del paisaje en el que se encuentra levantada la ciudad de Wari.

\section{LAS ESTRUCTURAS ARQUEOLÓGICAS}

\section{A. Las Canteras}

\section{Cerro San CRistóbal (2,825msnm.)}

Cantera más grande y cercana a la ciudad es sin duda el cerro San Cristóbal que tiene como sectores colindantes por el norte a Cercaduyoc y Cheqo Huasi, hacia el sur Quebrada Tarahuayqo, al este Huari Pampa y Qatuspunku y al oeste Corral Pampa y Cheqo Huasi. En el frente norte de la colina se encuentra la Cueva del Infiernillo con laberínticos pasajes internos excavados a manera de túneles de donde se extraía material antiplástico o temperante (arcilla fina) para la elaboración de cerámica, los túneles tienen más $100 \mathrm{~m}$ de longitud, ingresando a la cueva uno está a la derecha y el otro a la izquierda ambos recorren un espacio curvo cuya planta se asemeja a las tenazas de un alacrán la superficie de los túneles es irregular con piedras caídas del techo de la cueva y abundante tierra suelta con presencia de restos óseos, resultado de enterramientos prehispánicos hechos en el lugar, lo cual se diferencian claramente de algunos contextos de entierros contemporáneos de la época de la violencia. Descendiendo por la boca de la cueva existe un bloque de piedra parada a modo de huanca rodeada de piedras menores a manera de un altar donde los antiguos habitantes debieron de realizar ritos y ceremonias al Ukupacha. La oscuridad de la cueva no permite visualizar las paredes y techo. Infiernillo fue sin duda la pacarina de mayor magnitud en la metrópoli Wari, de la que se ha formado diferentes leyendas y creencias, y donde en la actualidad los pobladores del lugar concurren a dejar ofrendas de dulces, frutas, caracoles marinos, agua florida, etc., para el cuidado de ganado, bienestar familiar y producción agrícola.

En el extremo sur de la cima del cerro San Cristóbal, existe una extensa hondonada que corresponde a una de las cantera más grandes de piedra con abundante desechos de piedra picada (Fig. 2) y en el lado sureste de la indicada cantera hay otra cueva conocida como Intipunku, orientada precisamente en dirección a la salida del sol, el interior presenta un declive con tierra suelta que se extiende por lo menos a $30 \mathrm{~m}$ de profundidad hasta donde se puede tocar el techo rocoso de la cueva, a semejanza de la boca de una mina. En el lado oeste debajo de las peñas verticales que forman la cima existe también otra cueva que los pobladores de vista alegre la conocen como Machaypampa, a diferencia de las anteriores forma un espacio plano de $10 \mathrm{~m}$ de largo por (norte-sur) por $12 \mathrm{~m}$ de ancho (este-oeste), con entrada orientada a un amplio espacio abierto o pampa de donde proviene el nombre de la cueva (Machaypampa), en la parte central del interior de la cueva hay una piedra parada de 1.60 colocada intencionalmente a manera de huanca, asegurada en su base con piedras menores y rodeada de otras piedras menores dispuestas alrededor de la piedra central que debió funcionar como un altar. El techo de la cueva tiene salientes irregulares de roca de origen incandescente, en la actualidad es la cueva donde solo los pobladores de Pacaicasa acuden a depositar ofrendas o pagos (pagapus) para la cría y reproducción de ganado. Se conecta a la cima a través de un camino angosto que baja por el lado norte de la peña que forma la entrada de la cueva (Fig. 3). El infiernillo y el cerro San Cristóbal fue explorado por Tello (1942/2014) y Flores (1943). 


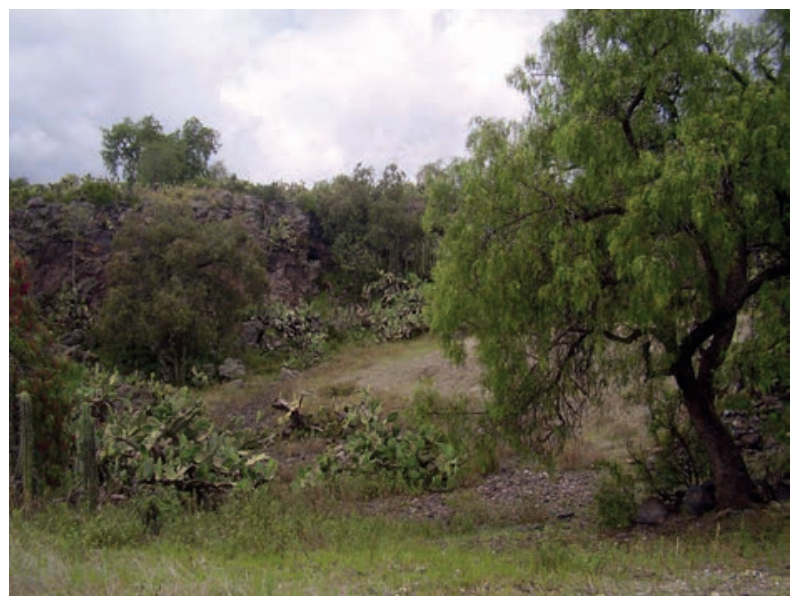

Fig.2. Cantera del cerro San Cristóbal.

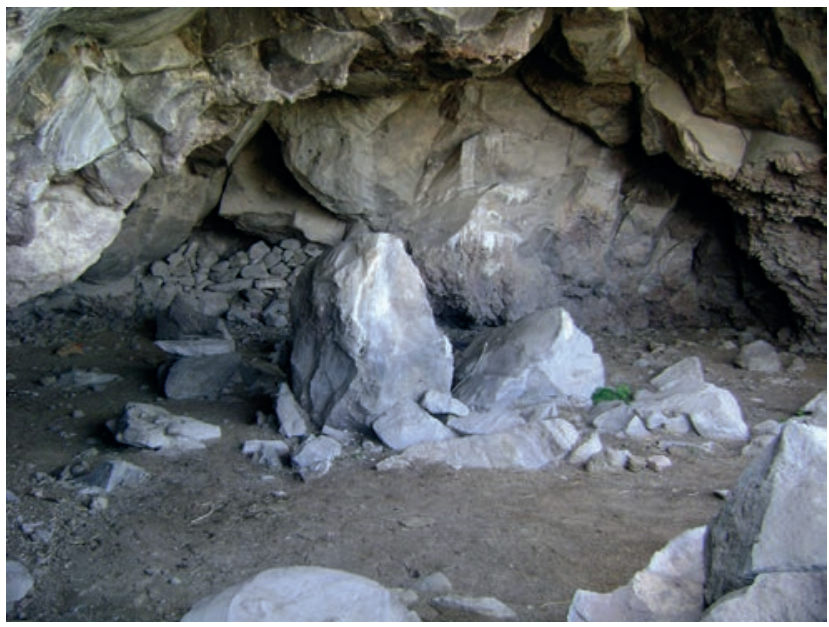

Fig. 3. Cueva Machaypampa lado oriental del cerro San Cristóbal.

\section{JAYWACANCHE (2 900 MSNM.)}

Cantera de arcilla en la ladera noreste del cerro Vilcarangra (8562400N/ 584300E), de este yacimiento se obtiene arcilla para el actual procesamiento de cerámica por los alfareros de Allpaorquna y Huayhuas en Huanta, práctica que debió de realizarse desde tiempos prehispánicos.

\section{YANAQOCHA C (4 100 MSNM.)}

Canteras de piedra andesita, localizada en la margen derecha del curso superior de la quebrada Ayahuarcuna, a menos de $1 \mathrm{~km}$ (8567100N/594700E). Al SO de la laguna Yanaqocha, y a $100 \mathrm{~m}$ aprox., sobre el actual camino que llega hasta la laguna. La piedra obtenida de esta cantera es la misma que aparece en la construcción del canal tal como se puede apreciar en el borde del camino que conduce a la laguna y corresponde al muro de contención del lado derecho de la referida canalización (Fig. 4). 


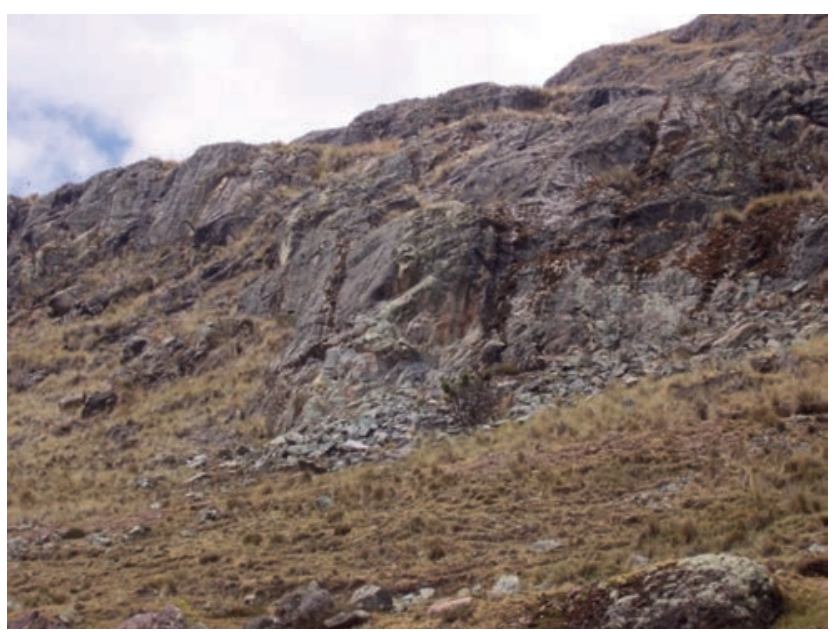

Fig. 4. Cantera de piedra basalto utilizada en la construcción del canal

\section{CURI ORQo (4 250 MSNM.)}

Cantera de tierras de color localizadas en la margen izquierda superior de la quebrada Condorcunca ( $8561100 \mathrm{~N} / 598700 \mathrm{E})$, los colores de arcilla que existen en pequeños socavones así como en afloramientos a nivel de superficie son amarillo, rojo, violeta y marrón. Estas canteras estas junto al camino que va hacia la laguna Yanacocha Grande.

\section{WALLPAQASA (3 840 MSNM.)}

Corresponde al cerro más alto de la periferia inmediata de la zona urbana de Wari (8555700N/588300E), se extiende longitudinalmente de sureste a noreste presenta diferentes promontorios separados por pequeñas abras, una de estas denominada Rayusca fue explorada por Tello en 1942. En toda la extensión hay afloramientos, cuevas y piedras con trabajadas que señalan haber sido una de las más grandes canteras, pero también hay piedras con petroglifos, pocitos y una serie de tallados en forma de canales o canaletas sobre grandes bloques de basalto., en el extremo suroeste del cerro se encuentra Suytu Rumi, donde resalta una piedra tallada en forma de sapo o janpatu, y en el espacio que lo separa con el cerro Chaupi Orqo hay distintos niveles de terrazas construidas a modo de dique para acumular agua en tiempo de lluvia en la extensa pampa que existe en el lado oeste de Ayamonte.

\section{QAtuspunku/ Ayamonte/ Quccĩumogo (2 845 mSNM.)}

Promontorio contiguo al lado sureste del cerro San Cristóbal, carretera Ayacucho- San Francisco Km. 9+100 Dv. Huanta - Quinua (8555400N/588100E), delimitado hacia el oeste por la naciente de la quebrada Tarahuayqo, hay una cantera de piedra basalto, en cuyo entorno se ha registrado más de 20 piedras con petroglifos en la variedad de pocitos circulares, representaciones del árbol Pati, hoyuelos y talladuras en grandes bloques dispuestos en forma de " $U$ " a modo de altares. Cabe anotar que en los perfiles de la carretera se observan restos de arquitectura de diferentes ambientes enlucidos y pintados de blanco, superposición de pisos de diatomita, drenajes, adosamientos y murallas que estarían delimitando a un determinado sector urbano de alto rango social en la periferia este de la ciudad, adyacente a la ocupación doméstica (Fig.5). 


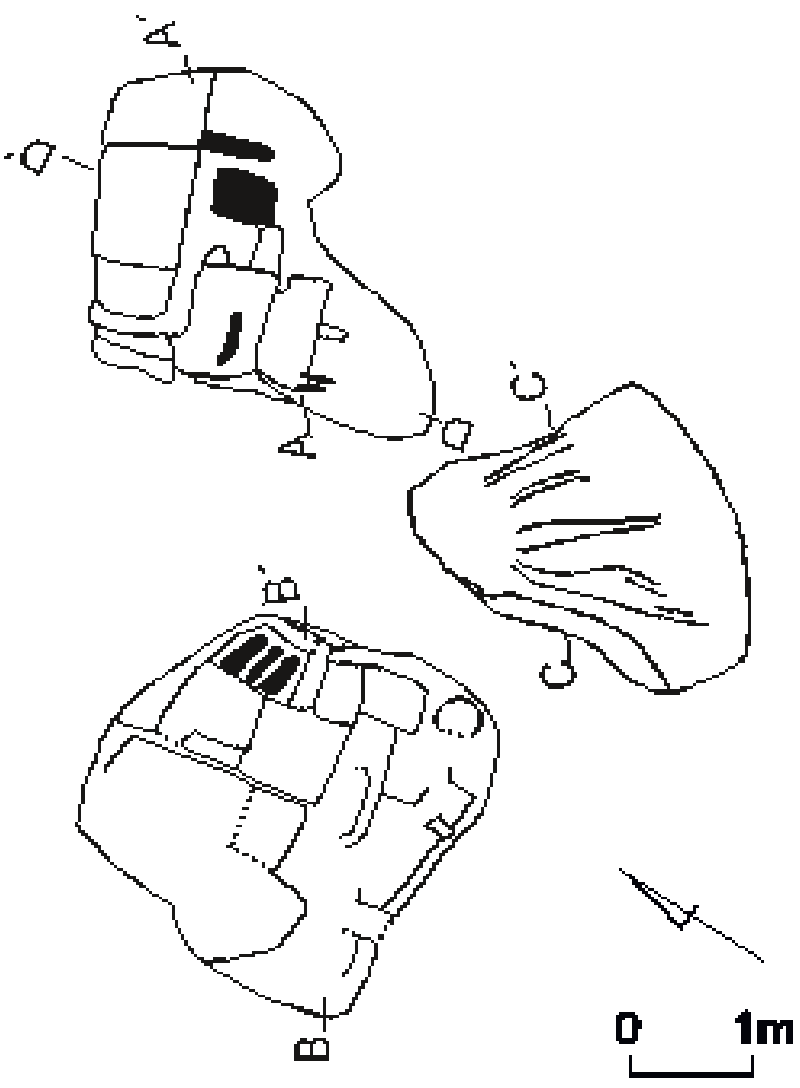

Fig. 5. Petroglifos en piedras dispuestas a manera de un altar en forma de "U" en Qatuspunku /Ayamonte.

\section{ZAPALlojASA (2 840 MSNM.)}

Promontorio contiguo al lado sur de Ayamonte (8555300N/588200E), separado por dos canteras de piedra con abundante desecho en medio de afloramientos de roca volcánica, en los que destacan 15 bloques con canaletas, pocitos y talladuras a manera de maquetas, en la superficie principalmente en el lado oeste existe abundante fragmentos de cerámica Huarpa y Wari, a los que se incluye la presencia de cerámica Cajamarca cursivo floral. La zona corresponde también a una cantera de piedra con varios bloques en proceso de tallado.

\section{TORRESPAMOQO (2 850 MSNM.)}

Adyacente a Zapallojasa, pero de mayor extensión y elevación que Ayamonte (8555200N/588500E), presenta numerosas rocas salientes dentro de los que se ha documentado más de 20 petroglifos, entre pocitos, canaletas, hoyuelos, talladuras volumétricas de formas arquitectónicas y piedras talladas a manera de mesas que hacen pensar en altares, existe además dos canteras una en el lado sureste de la cima y la otra en la ladera norte, en esta última hay graderías megalíticas talladas en la misma roca y en las cercanías otros bloques en proceso de tallar dando la impresión de haber sido el lugar de donde tallaron a los monolitos. 


\section{Nueva EsPeranza (3 300 mSNm.)}

Cantera de arcilla y tierra de color amarillo visible en los perfiles del camino que pasa de oeste a este el centro poblado Nueva Esperanza, donde viven varias familias que producen cerámica tradicional (8559100N/595500E).

\section{SULLUHUASI WAYqo (3 100 MSNM.)}

Canteras de arcillas de tonalidades amarillentas y rojizas, en el lado sur de la pampa de Ayacucho, margen derecha de la quebrada Sulluhuasi Wayqo (8559000N/595300E), que alcanza considerable profundidad a la altura del pueblo, existe entre dos a cuatro canteras que los alfareros de Quinua continúan aprovechando.

\section{Checclla Huayco (2 650 msnm.)}

Canteras de arcilla de coloración marrón y rojiza, en ambos lados de la quebrada Checclla Huayco en una extensión aproximada de $01 \mathrm{~km}$ altura aguas abajo descendiendo por el pueblo de Mitoqasa (8553700N/587300E), donde existe restos de un antiguo camino, por el que accedió Julio C. Tello y sus acompañantes en la expedición de 1942. Son las canteras con mayor volumen de capas de arcilla, separadas por gruesas láminas de roca volcánica como las que están estas las mesas líticas encontradas en Vegachayoq Moqo, son las canteras más cercanas a la ciudad de Wari, comprende también afloramientos de diatomita utilizada para la elaboración de pisos y enlucidos (Fig. 6).

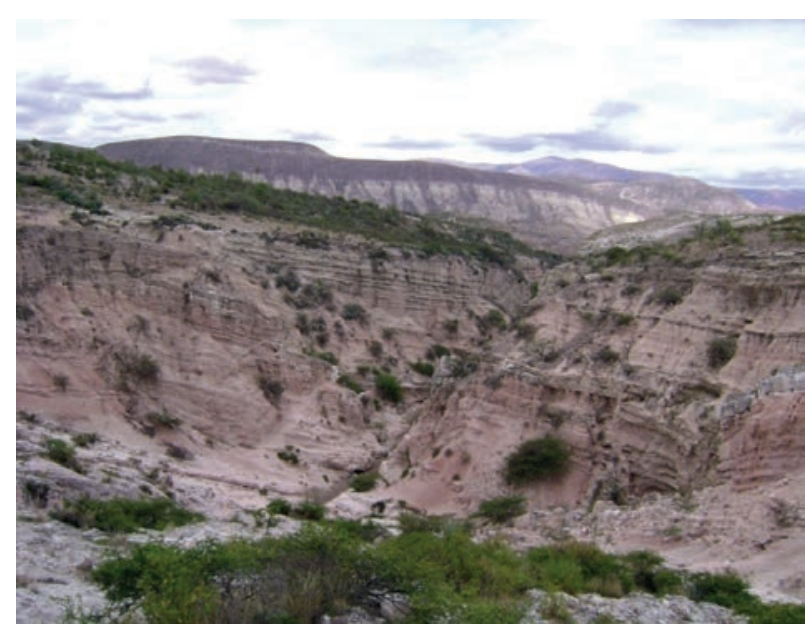

Fig.6. Canteras de arcilla en la quebrada Checclla Huayqo.

\section{B. Las cuevas}

\section{Pikimachay (2 990 mSNM.)}

Cueva con ocupación precerámica, localizada en la ladera meridional del cerro Leqlespata o Ccorihuayruna (8558798N/583960E), está delimitado por dos riachuelos que se unen a la quebrada Pacayhuayqo, afluente de la quebrada Puchqo que alimenta de agua al río Ocopa en el anexo Orcasitas del distrito de Pacaycasa, fue explorada y excavada por un equipo de especialistas dirigido por Ri- 
chard MacNeish entre 1967 y 1971 quienes lograron definir restos de fauna pleistocénica (armadillo gigante perezoso y tigre diente de sable) sobre el lecho de la cueva, con una antigüedad que oscila entre los 18,000 y 13,000 a.C. a la que le denominaron fase Pacaicasa, sin pruebas contundentes de artefactos elaborados por la actividad humana, sobre la que superponen restos de camélidos, caballo, roedores, zorro y puma asociados irrefutablemente con instrumentos líticos de fábrica humana, en su mayor parte puntas de proyectil, raspadores, raederas, hachas y buriles atribuidas a la fase Ayacucho, cuyos restos óseos otorgan una antigüedad de 13,000 a 11,000 a.C.

La cueva de Pikimachay continua al parecer ocupada en la fase Huanta y Puente (11,000-9,000 a.C.) tiempo al que se asocia el desprendimiento del techo de la cueva y un abandono de aproximadamente 6,000 años para luego ser reocupada durante a partir de la fase Chihua hasta la época Chanka, según el resultado de radiocarbono 14 (MacNeish, et. al. 1981), (Fig.7).

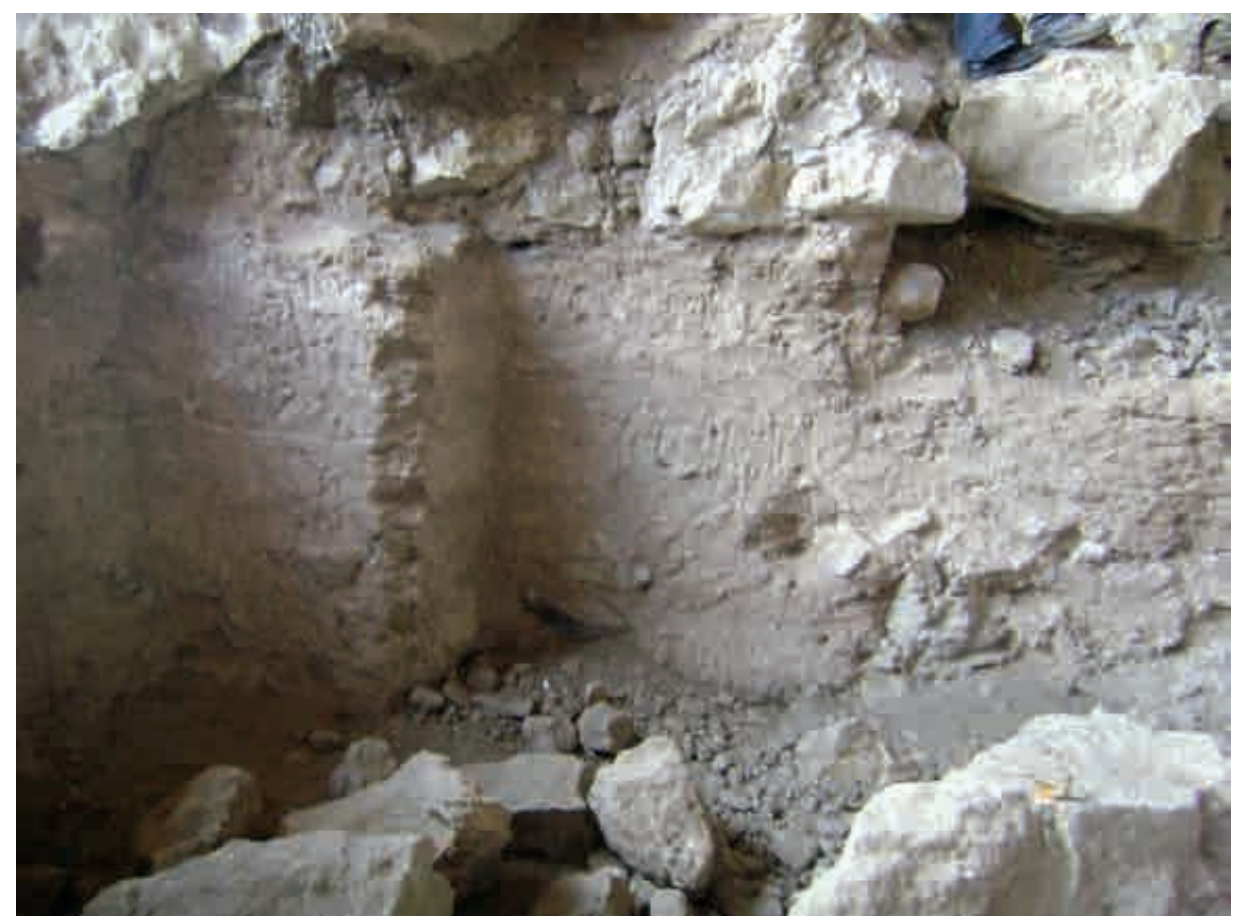

Fig. 7. Perfil estratigráfico excavado por el equipo de Mac Neis 1971

\section{UCHUYPIKYMACHAY (3 050 MSNM.)}

Cueva con arte rupestre localizada a unos $400 \mathrm{~m}$. al noroeste sobre la cueva de Pikimachay (8559000N/583400E) es de menor magnitud, pero presenta también parte del techo caído y espacios con evidente ocupación cultural, en el centro de la cueva aflora la superficie de la roca, donde existe un conjunto de petroglifos con motivos de líneas curvas que parecen representar a determinadas figuras de plantas y animales. Esta cueva al igual que la cueva vecina de Pikimachay considerada como residencia de los wamanis a donde los pobladores del lugar recurren a depositar ofrendas o pagapus (Figs. 8 y 9). 


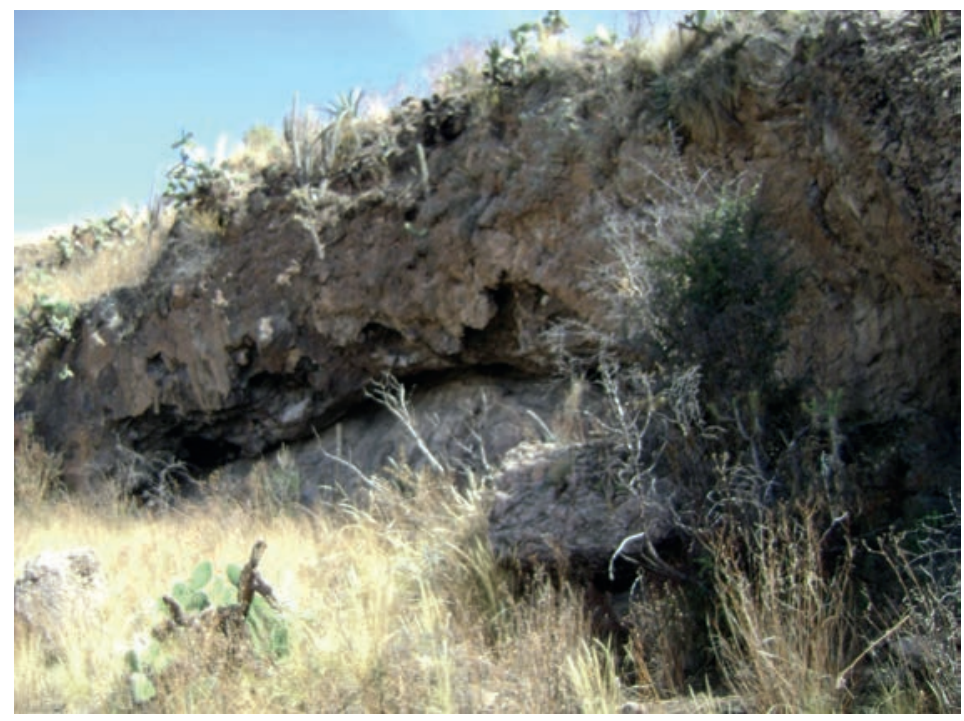

Fig. 8. Cueva o abrigo de Uckuypiquimachay.

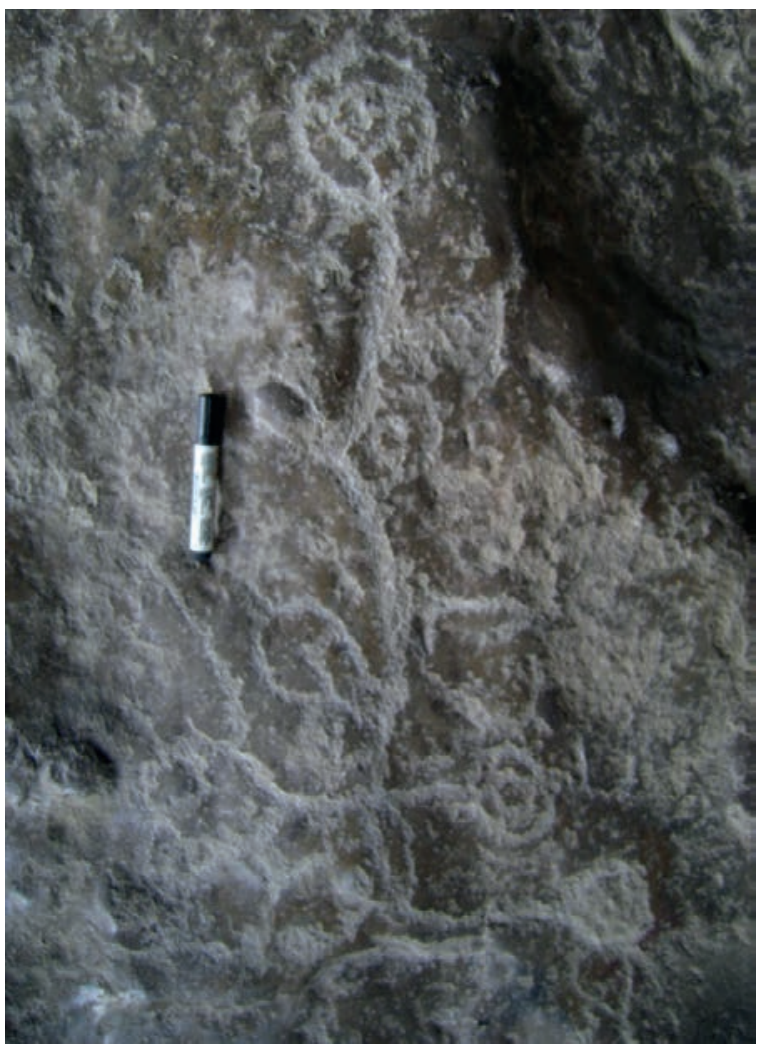

Fig. 9. Representación de una planta (papa) en los petroglifos de Uchuypiquimachay. 


\section{Ayamachay (2 900 mSNM.)}

Dista de Pikimachay a menos de $01 \mathrm{~km}$ al sur de Pikimachay, ladera sureste del cerro Chaqohuillca $(8558500 \mathrm{~N} / 583900 \mathrm{E})$, mide $9 \mathrm{~m}$ de este-oeste, $8 \mathrm{~m}$ de profundidad, y solo 2 a $4 \mathrm{~m}$ de alto. Tiene más de 9000 años de ocupación.

MacNeish et al. (1981), informa que el estrato de ocupación más temprana es de ceniza, carbón compacto y un fogón a lo largo de la pared este de la cueva asociado con artefactos del tipo Puente Tardío, $7250 \pm 350$ a.C., lo cual con la cantidad limitada de de restos de un venado, un camélido, un cuy, y una ave sugiere una ocupación muy corta. El fogón y el área con ceniza sugieren la corta de una microbanda de familia nuclear, quienes despellejaron y pelaron pieles, repararon sus herramientas, y quizás trabajaron el hueso. Mientras que los estratos más tardíos corresponden a las capas superiores asociadas con huesos de cuy, camélidos, una pieza de hilo, prendas de algodón entrelazado, y muchos fragmentos de Huamanga Tardío de cinco ollas, que datan entre 950 -1350 d.C. y finalmente la capa superior con tierra quemada y de estiércol tenía algunos artefactos, principalmente raspadores, algunas piezas de huesos no identificables, restos de plantas, dos piezas de pellejo, varios fragmentos Chanca, y un fragmento colonial, sugiriendo una ocupación u ocupaciones entre los 1200 - 1700 d.C.

\section{Rosamachay (Cueva de Rosie) (2 877 mSNM.)}

Registraday excavada por MacNeish en 1969. Se ubica a $2 \mathrm{~km}$ al norte de Pikimachay, margen izquierda de un pequeño cañón que drena de ooeste a a este en el largo Cañon Chihua (8561900N/584700E). Está en un pequeño acantilado de $50 \mathrm{~m}$. de largo y mide $10 \mathrm{~m}$. de largo, $9 \mathrm{~m}$ de profundidad por $3 \mathrm{~m}$ de alto en la parte más abierta de la boca. La ocupación más representativa esta representa por restos de mazorcas de maíz con fechado radio carbónico de $3300 \pm 105$ y $3250 \pm 100$ a.C. Los arqueólogos registraron huesos y fetos de cuy asociados a un fogón con moledores, raspadores, lascas, bifaces, núcleos; que sugieren una visa sedentaria de un grupo de una microbanda o familia. Las ocupaciones más tardías tienen cerámica Chupas de 700 a 500 a.C. asociado con huesos de venado, camélido, canes (perros), aves y cuyes, al igual que fragmentos de cerámica tipo Rancha de $400 \pm 100$ a.C. También se hace referencia de una punta de proyectil Wari, un fragmento Wari policromo, y un vidrio en esta capa superficial de ceniza y estiércol mezclado. No se tiene exactas estimaciones de actividades u ocupaciones, según Mac Neish et. al. (1981), (Fig. 10).

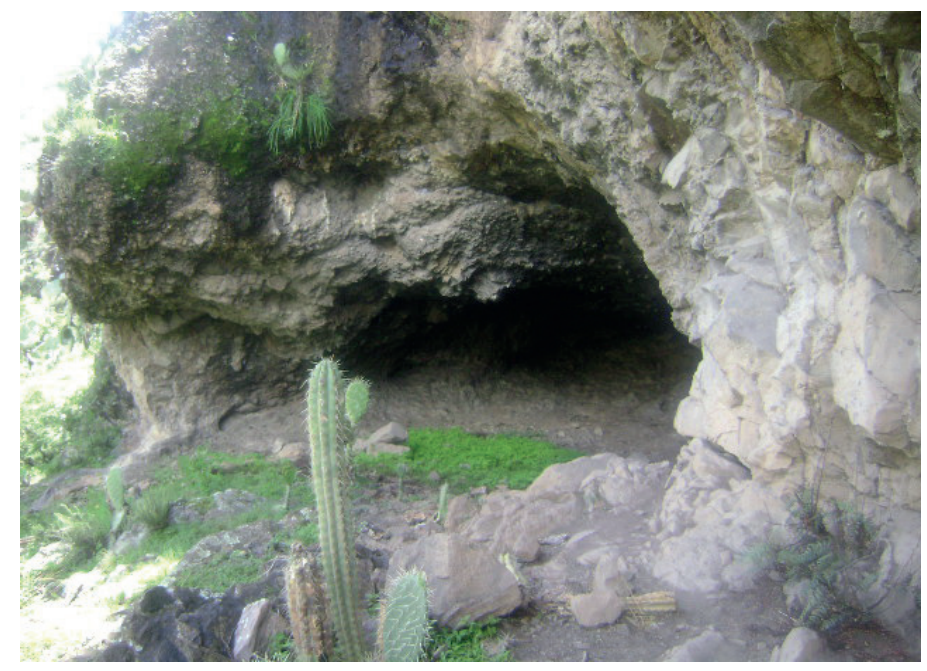

Fig. 10. Vista general de la boca de la cueva. 


\section{RUYRu Rumi (4 150 MSNM.)}

Abrigos debajo de un bloque de roca, se encuentra en el lado este del valle encima del camino que va de Quinua a la selva (8562900N/598300E), ladera de la margen izquierda de la quebrada Pallcca, se trata de dos abrigos que ocupan los lados norte y sur. El del lado sur es de $14 \mathrm{~m}$ de largo, este-oeste, por $9 \mathrm{~m}$ de ancho norte-sur, mientras el abrigo norte es de $12 \mathrm{~m}$ este-oeste por $8 \mathrm{~m}$ norte-sur. El asentamiento fue localizado por MacNeish, García, y Wiersum en 1969, quienes dan cuenta del hallazgo de puntas de proyectil tipo Jaywa, en su mayor parte de obsidiana asociada a huesos de un venado adulto deja pocas dudas que una de las funciones principales de esta ocupación fue la caza de animales silvestres, la otra actividad principal parece haber sido el de reparar armas, por la presencia de fragmentos de puntas de proyectil, núcleos de basalto local, astillas y lascas, algunos artefactos hechos en obsidiana de Huancavelica y otros de obsidiana local, indicando que en este tiempo (fase Jaywa) se vivió un comercio con esa región llevada por los cazadores. El hallazgo de raspadores sugiere haber sido utilizado para el cortado de carne y el despellejamiento. Ellos también pudieron haber sido usado para raspar piel, pero aquí las herramientas del comercio fueron probablemente extremos de raspadores de la variedad fina.

La posibilidad de otra actividad, queda representada por dos fragmentos de cráneos humanos erosionados; si esto fue canibalismo o parte de un ceremonialismo funerario es desconocido, evidencia de lo cual es más frecuente en ocupaciones de la estación seca en las partes bajas. Quizás ellos son sólo inclusiones accidentales como las asociadas a rasgos culturales no discernibles. La ocupación Jaywa ocurrió aproximadamente de 8000 a 6200 a.C, parece haber sido típica, en una estación seca, una microbanda o familia nuclear cazando en la Puna. No hay forma si podemos interpretar como una ocupación sedentaria anualmente, y contrasta con contemporáneas ocupaciones Jaywa largas y grandes en la estación húmeda en las partes bajas, seguido de una ocupación con cerámica de tipo Wichqana negro, Kichkapata, y Chupas con un fechado de $1050 \pm 150$ a.C., y algunos fragmentos Huarpa Negro-sobre-Blanco, Caja, Kumun Senqa y Cruz Pata de aproximadamente de 350 a.C. - 250 d. C y de los tipos Aya Orqo con pintura negativa Huamanga, Ramos Chayoc y Arqalla que sugieren que las ocupaciones más numerosas fueron de tiempos Huamanga, aproximadamente de 900 d.C. a 1300, MacNeish, et.al. 1981.

\section{LOS ACUEDUCTOS}

\section{PAmpachacra (2 900 mSNM.)}

Ubicado en el anexo Pampachacra (8556200N/590100E),m parte alta del complejo Wari, presenta corte transversal escalonado de aspecto trapezoidal, mide aproximadamente $150 \mathrm{~m}$ de largo, $15 \mathrm{~m}$ de alto, 30 de ancho en la base y 3 a $4 \mathrm{~m}$ de ancho en la parte superior por donde pasa el canal. Se trata de una imponente obra hidráulica construida con muros de contención y rellenos de tierra traída de lugares cercanos, los paramentos escalonados presentan evidencias de haber estado enlucidos. El canal que pasa por la parte superior mide entre 50 a $60 \mathrm{~cm}$. de ancho por $70 \mathrm{~cm}$ de profundidad (Fig.11).

\section{Los CAMINos}

\section{TABLAPAMPA (2 850 MSNM.)}

Tramo de camino Wari visible en más de $01 \mathrm{~km}$ de extensión desde la parte alta próximo a la Vega hasta Pacaycasa, correspondiendo a la descripción a la parte que pasa por el asentamiento de Tablapampa, donde se observa las hileras de piedras que delimitan el camino que conserva entre 6 a $8 \mathrm{~m}$ 


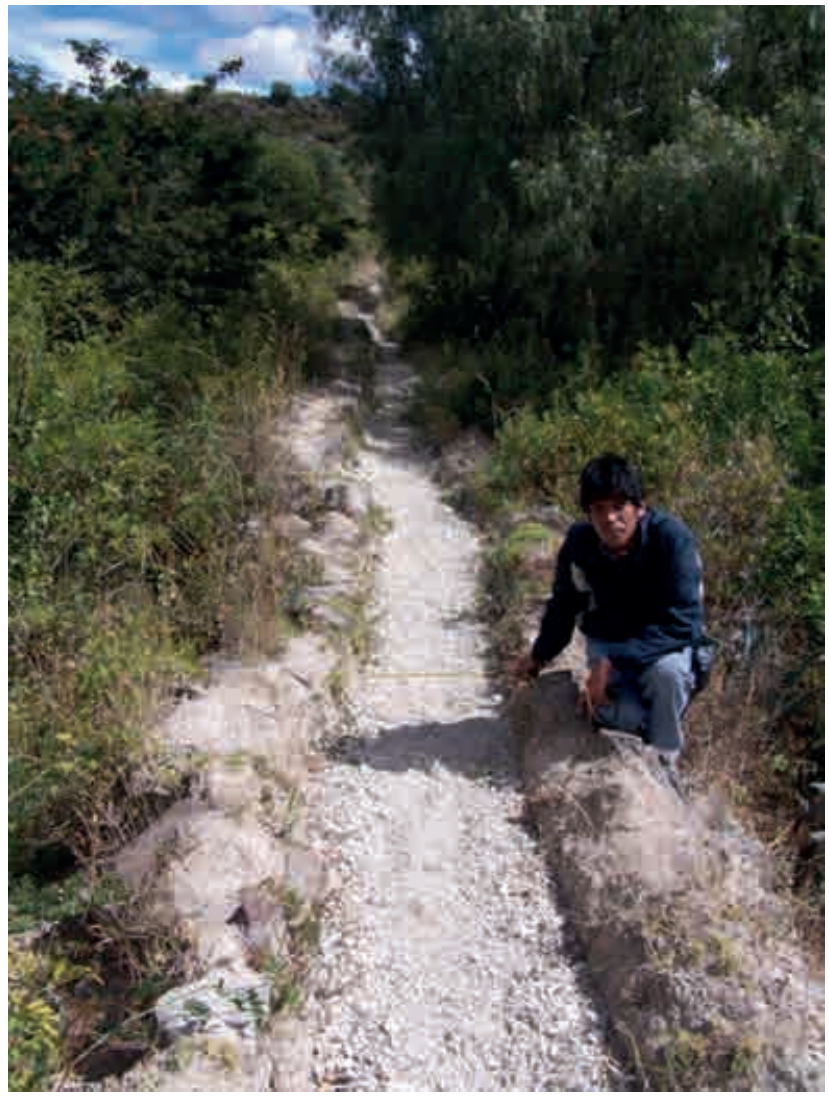

Fig. 11. Montículo por donde pasa el acueducto de Pampachacra.

de ancho. Tablapampa es una meseta delimitada por pendientes de las quebradas Pacayhuayqo, Pochqoq y Senqenqo, al noreste del pueblo de Pacaycasa (8558200N/585700E), el área cultural del sitio abarca entre 10 a 15 has, desde el extremo sur de la meseta hasta la parte central, siendo la parte alta la menos ocupada. Se caracteriza por presentar arquitectura monumental consistente en un canchón de 72 x 77m delimitado por altas murallas y plataformas en distintos niveles que la convierten en una eminente obra monumental producto de un trabajo mancomunado debidamente planificado. Hacia el lado sur del canchón, continúa una densa ocupación doméstica con abundante cerámica formando áreas contextuales específicas con fragmentos de cerámica que corresponden desde el período Formativo Superior (estilo Caja), Desarrollos Regionales Tempranos (Huarpa y Cajamarca) y Wari. El camino pasa por el lado norte del asentamiento se superpone a viejas estructuras de la época Huarpa, lo cual requiere de mayor investigación (Fig.12).

\section{Huaynahuillca (3 150 mSNM.)}

Terrazas agrícolas y otras estructuras asociadas a las laderas y cimas del cerro Huaynahuillca cercano del sitio anterior (8558800N/581200E), los restos de un caminos conecta al complejo sistemas de terrazas que circunda al cerro por el lado norte, rematando en una plataforma superior donde se observa un conjunto de estructuras circulares con paredes derruidas y circundadas por un muro perimétrico, parecen corresponder a estructuras funerarias. El sitio es venerado por los pobladores del 


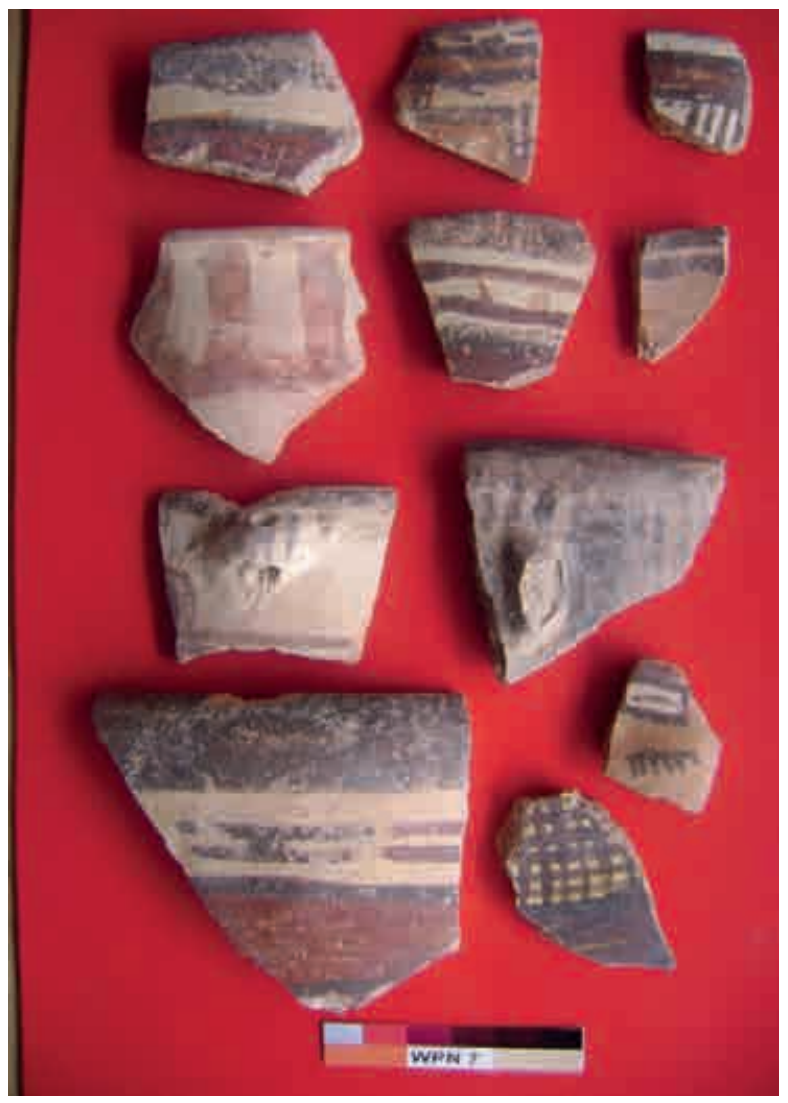

Fig. 12. Cerámica Huarpa Negro sobre blanco y tricolor de Tablapampa

lugar quienes la consideran como "apu" y acostumbran a dejar ofrendas o pagapus. Recorriendo por el lado sur contabilizamos cerca de un centenar de terrazas escalonadas y un camino que conecta a una plaza para luego ascender hacia el cerro de Hornuyoc.

\section{LA VEGA (2 980 MSNM.)}

Camino y estructuras dispuestas al pie de la carretera que va a Huamanguilla, altura del pueblo 24 de Junio y Maranniyoc (8560050N/587050E), las estructuras son visibles a lo largo de un camino de herradura desde borde de la carretera hasta el borde de una quebrada que baja al valle de Huanta. Las estructuras tienen entre 50 y $60 \mathrm{~cm}$ de ancho y están dispuestas en forma paralela entre 10 y $15 \mathrm{~m}$ de distancia, en la parte baja del área forma un recinto cuadrangular de 10 x $10 \mathrm{~m}$. y aproximadamente a $100 \mathrm{~m}$. hacia el oeste existe el tramo de un antiguo camino de $4 \mathrm{~m}$. de ancho, delimitados con muros visibles en más de $20 \mathrm{~m}$. de largo orientado de noroeste a sureste; la cerámica asociada a la superficie corresponde a las épocas Huarpa y Wari, pero también hay abundante material lítico en pedernal, jasped, obsidiana y cuarzo.

\section{Chalhuarangra (3 624 mSnM.)}

Restos de camino y canal antiguo dispuestos en la margen izquierda de la quebrada Chalhuarangra afluente del río Hayahuarcuna (8564449N/ 591540E), ambos vestigios recorren de manera parale- 
la al cauce longitudinal de la quebrada con excepción del canal que a cierta distancia del camino aguas abajo cambia de recorrido hacia el sur.

\section{Ayahuarcuna (3 164 mSNM.)}

Camino prehispánico cruza de sur a norte la quebrada Ayahuarcuna (8563041N/587906E), en unas partes mide $8 \mathrm{~m}$ de ancho y en otras principalmente laderas llaga hasta $3 \mathrm{~m}$ de ancho, el camino se observa cruzando la quebrada Hayahuarcuna en unos 500m de largo, se trata al parecer del camino Inka que viene por Chiwa y que llega a Huamanguilla pasando por Macrachacra.

\section{Ayahuarcuna (2 927 MSNM.)}

Camino con escalinata en la confluencia de las quebradas Huayunga y Ayahuarcuna (8561700N/ $586000 \mathrm{E})$, las graderías están talladas en la misma roca, el camino se proyecta por el cauce longitudinal de la segunda quebrada.

\section{Ayahuarcuna Puente (2 927 mSnM.)}

Se trata del puente colonial con arco, hecho de cal, arena y piedra, ubicado a unas 300 aguas abajo del puente actual de la carretera Ayacucho-Huanta (8561800N/585500E). El puente tiene base sólida de piedra donde es probable que haya existido un puente prehispánico para unir al camino que desde tiempos pasados ya se venía usando.

\section{ChIWA (2 500 MSNM.)}

Camino prehispánico, recorre de norte a sur el lado oeste del cañón de Chiwa (8563400N/583200E), donde lo más impresionante es un tramo empedrado con muros de contención que se inician sobre la roca madre en las partes con rellenos sólidos que mantienen bien conservado al camino, en algunas partes los muros de contención están hechos a manera de plataformas. El camino tiene graderías, descansos y drenajes, estos últimos para evacuar el agua en tiempo de lluvia. El tramo observado corresponde al camino que une Wari con Azángaro, el mismo que posteriormente fuera reutilizado e integrado al Qhapaqñan Incaico (Fig. 13).

\section{Allcohuillcca (3 020 MSNM.)}

Qocha y camino prehispánico, localizada en el abra formada entre la ladera de los cerros Molinuyoc y Churumoqo (8561900N/581900E), la qocha ocupa cerca de $1400 \mathrm{~m} 2$ en el lado norte de la actual plaza, donde se extiende bajo la construcción de las actuales viviendas, evidencia que se logró registrar cuando la zona fue utilizada como cantera para la fabricación de adobe así como cuando se abrieron zanjas para la instalación de agua potable por el año 2001, el fondo de la qocha contiene cerámica de filiación Formativa, Huarpa y Wari, probablemente arrasada por factores fluviales de las laderas del cerro Churo Moqo o bien que corresponda a objetos rotos durante la obtención de agua. El camino llega por el lado sur de la plaza y es el actual camino de herradura que baja por el cauce de la quebrada Saccalli, donde aún queda parte de graderías y cercado laterales.

\section{Chiwa (2 720 MSNM.)}

Restos de camino que baja por divisora de las aguas que bajan a la margen izquierda del cañón de Chiwa (8563700N/581100E). El camino comunica a la población establecida en la parte a la parte alta y baja del valle de Chiwa, como la siguen usando actualmente los pobladores de Ancuhuillca. 


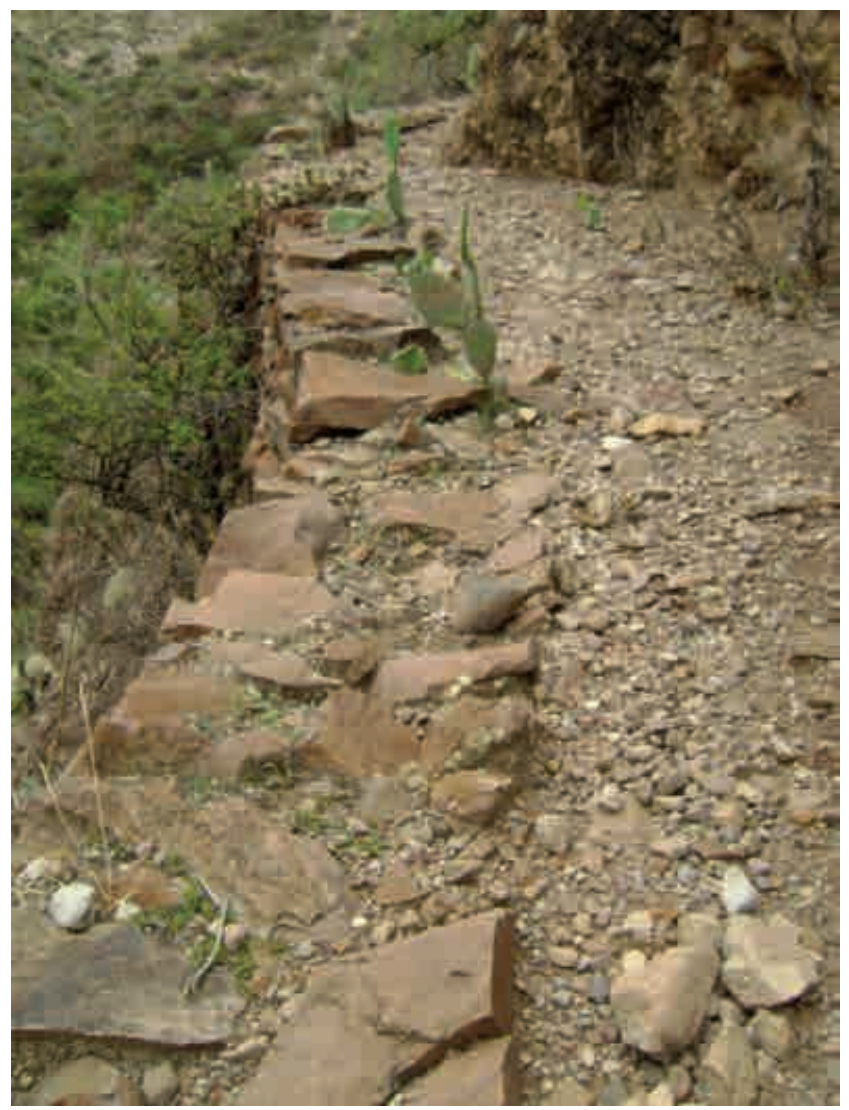

Fig.- 13. Restos de camino con restos de parapeto en el borde que da hacia el abismo.

\section{Condormarca B (3 900 MSNM.)}

Restos de camino prehispánico, pasa por margen derecha cerca del cauce de la quebrada Condormarca $(8564700 \mathrm{~N} / 594500 \mathrm{E})$, según referencia de los pobladores es el camino antigua que se sigue reutilizando, saliendo de Huamanguilla conecta con la selva del Apurímac pasando por Tambo y San Miguel. El camino aparece en partes delimitas con piedras paradas y en otras con graderías, el ancho varia entre 3 a $5 \mathrm{~m}$.

\section{CONDORCUNCA (3 750 MSNM.)}

Restos de camino prehispánico, que recorre la ladera sur del cerro Condorcunca (N $8559700 \mathrm{E}$ 595900), por donde sigue casi paralelo al cauce de la quebrada Andrespata en dirección a las lagunas Yanaqocha Chica y Grande.

\section{Ramospata (3 850 mSNM.)}

Restos de camino que atraviesa de oeste a este la parte alta de Huacaurara, el camino pasa cerca de Ayamonte (sitio 49) (8556100N/589100E), en partes aparece delimita con piedras paradas en ambos lados, mientras que en otros solo se observa un solo lado, junto al camino a la altura de Sancay-Corral 


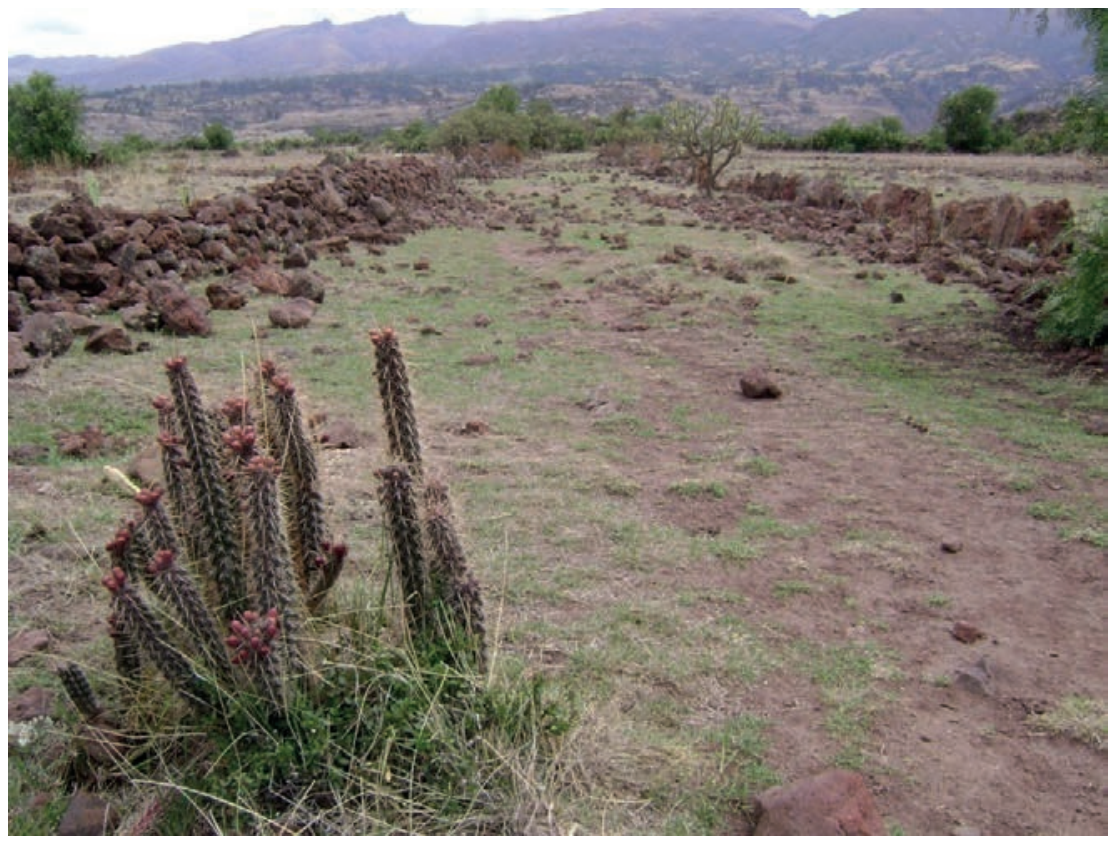

Fig. 14. Restos de antiguo camino que pasa por la parte alta del lado oriental de Wari.

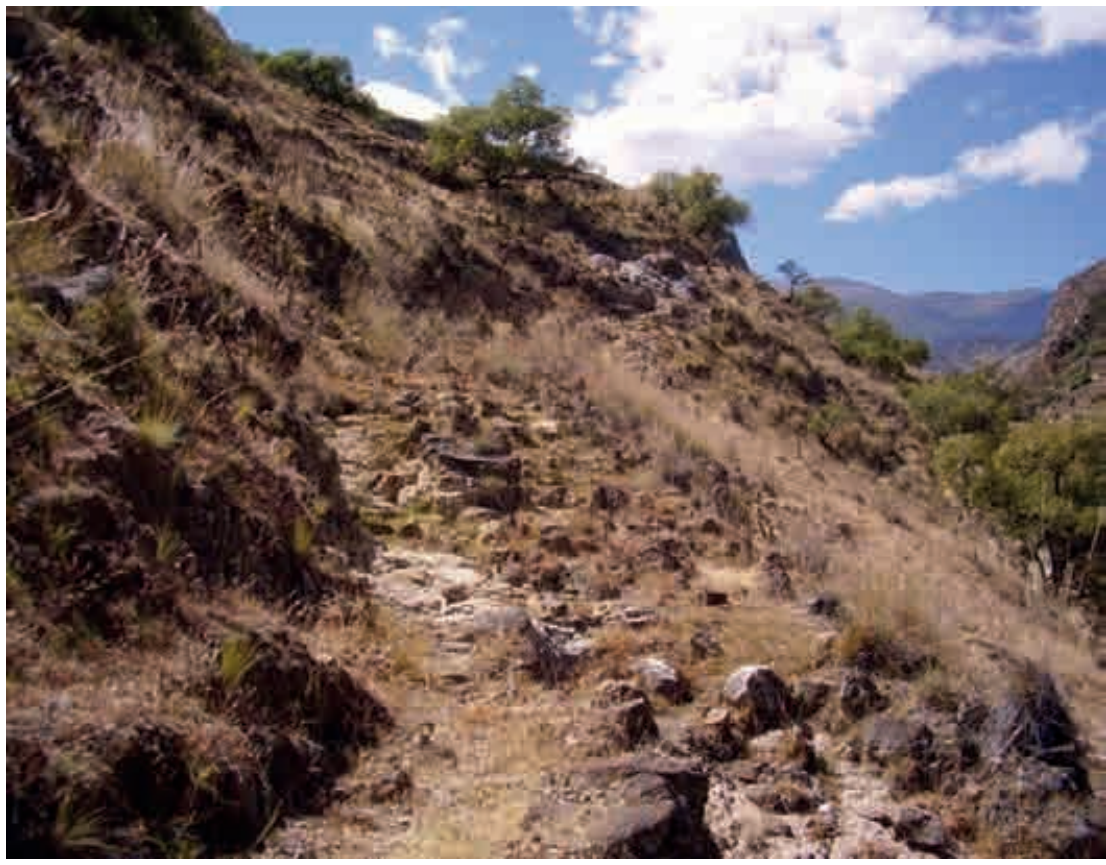

Fig. 15. Restos de antiguo camino en la margen derecha de la quebrada. Huancahura o Putica. 
hay ciertos alineamientos que integran otro asentamiento. Este camino continúa en dirección a Llamahuillca y sirve de límite entre Huacaurara y Pampachacra (Fig. 14).

\section{Putica (2 650 mSNM.)}

Camino prehispánico que recorre de oeste a este la meseta separada por los ríos Putica y LLuncuna (8558700N/588900E), las evidencias tienen entre 2.50 a 3m de ancho delimitado en el lado inferior con piedras paradas mientras que en el lado de la ladera con terrazas dispuestas en diferentes niveles, el camino se proyecta a la parte alta en dirección a Quiturara (Fig. 15).

\section{YACUTINCO (2 700 MSNM.)}

Restos de camino prehispánico, recorre en zigzag cruzando el valle de Yacutinco hasta llegar a la loma Huayranca en el curso medio del río Andrespata (8554800N/593400E), el camino va por partes delimitado con piedras paradas pero la mayor extensión del tramo se encuentra erosionado.

\section{Patasuyoc (3 100 mSNm.)}

Restos de camino antiguo que une a Huayranca con otros poblados cercanos, el camino va pegado a la ladera sur del cerro Patasuyo (8554000N/593100E), donde aparece reforzado con muros de contención y al borde de la ladera un muro de doble cara que lo convierte en una especie de callejón de 2.50 de ancho.

\section{ChUMAORQo (2 800 MSNM.)}

Restos de camino prehispánico, viene de norte a sur cruzando una extensa pampa (8551400N/594200E), se observa solo en algunas partes debido a que la carretera actual ha destruido el trazo original, la evidencia del camino se observa en el extremo norte de la loma Solórzano, donde se aprecia que el ancho es de 4 a $5 \mathrm{~m}$ y ambos lados están delimitados con hileras de piedras.

\section{ANÁLISIS Y CLASIFICACIÓN DEL MATERIAL RECOLECTADO}

\section{ESTILOS ALFAREROS}

\section{A. Estilo Rancha}

Definida por Lumbreras $(1959,1975)$, a raíz de trabajos efectuados en la colina de Aya Orqo localizado en la parte alta del lado suroeste de la ciudad de Ayacucho, considerada en el desarrollo del proceso histórico de Ayacucho como la fase cultural previa a Huarpa compartiendo ciertos atributos en las formas y tipo de bordes de las vasijas. La cerámica rancha se caracteriza por llevar engobe rojo con acabado pulido y bruñido en la parecen decoraciones en alto relieve así como tiras sobrepuestas e impresiones hechas con instrumentos punzo cortantes formas de vasijas como cuencos escudillas, ollas y cantaros con bordes redondeados y biselados y en algunos casos con reborde hacia el exterior, siendo también común las incisiones de líneas a la altura del cuello en algunas vasijas cerradas.

\section{ESTILO KuMUNSENQA}

Considerada como una variante de la cerámica Huarpa según Lumbreras (1975), Benavides (1965), González y Cahuas (1984), presenta como atributo engobe de color rojo o granate en el exterior y parte superior interna de las vasijas cerradas y abiertas en los que destacan ollas y cantaros de tamaño grande, las cuales por lo general presentan bordes o labios redondeados expandidos al exterior. El 
nombre de Kumunsenqa proviene de una colina ubicada en la margen izquierda del valle Totorilla, comprensión del barrio de la Magdalena.

\section{Negro sobre Blanco}

Corresponde a la cerámica clásica de la cultura Huarpa, segregada como unidad estilística por Rowe, Collir y Willey (1949), aun cuando a inicios de la década del treinta Julio C. Tello acompañado de Lila Oneale lo habían reconocido con algunos fragmentos recolectados en Tanta Orqo, en la parte baja del complejo Wari, mientras que Bennett (1953) a pesar de haberla encontrado en una posición estratigráfica más profunda que los elementos Wari, considera que la serie Huarpa de cerámica bicroma y tricolor pertenece a la etapa final de Wari, secuencia que no comparten Menzel (1968) y Lumbreras $(1960,1969,1975)$, quienes la ubican como un estilo que antecedió a la cerámica Wari, y según este último investigador la ubicación cronológica está corroborada con información estratigráfica y datación radiocarbonica de sitios excavados por el proyecto dirigido por MacNeish.

\section{Negro SOBRe AnTE}

Corresponde a una variedad del Huarpa Bicolor con las mismas formas y características morfológicas del estilo Negro sobre Blanco, pero con la diferencia que el engobe o base decorativa es de color ante o anaranjado claro, en algunos casos parece corresponder a la superficie natural de la vasija.

\section{Rojo SOBRe ANTE}

Variedad segregada del grupo Huarpa bicolor, se distingue de los anteriores por el color rojo de líneas gruesas pintados sobre el color ante o fondo natural en la parte superior y media exterior de vasijas abiertas y cerradas de manufactura modelada. Esta variedad tiene mucho parecido con la cerámica Caja del los inicios del Intermedio Temprano en Huancavelica.

\section{HuARPa Tricolor}

Reconocida así por Bennett (1953), y como Huarpa Tricolor por Benavides (1983) Knobloch (1991), Cabrera (1998) y Leoni (2009), y una variante en que se agrada el color rojo violáceo a semejanza del engobe de Kumunsenqa y Cruz Pata según Lumbreras (1975), corresponde a la cerámica donde se percibe influencia de la cultura Nasca tanto por el color blanco que sirve de base así como en los diseños de animales marinos representados a veces en líneas rectas y otras en líneas curvas, pero también hay representaciones de círculos y triángulos concéntricos, franjas con volutas o espirales, figuras que se asemejan a hojas de maíz, líneas rectas gruesas y paralelas, alternadas a veces con líneas onduladas y en otras con trazos en zigzag, pintados de una variedad de tonos blancos, cremas, rojos, granates, anaranjados, violáceos, marrones y negros, en vasijas abiertas y cerradas de manufactura modelada.

\section{Cruz Pata Rojo - Marrón}

Se trata de una variedad del estilo Cruz Pata definido por Benavides (1965), Lumbreras (1975), reconocido como Huarpa por Menzel (1968), Huarpa Derivado según Knobloch y Cruz Pata Rojo y Marrón por Leoni (2009) a partir de sus recientes trabajos en Ñawimpuquio. Las vasijas son modelados a mano, la mayoría presentan bordes redondeados, aunque se presentan casos, generalmente en los golletes de los cántaros, de un borde plano ligeramente redondeado al interior y otro redondeado engrosado al exterior, los cuellos son evertidos al interior y exterior, con cuerpos elipsoides y curvo divergente, de bases planas o redondeadas, a veces con depresión central. Los diseños son de líneas, franjas y puntos pintados de color negro, marrón y blanco sobre engobe rojo o marrón, hay también otra variedad que presenta el fondo negro y anaranjado. 


\section{EsTILO OCROS}

Identificado por Julio C. Tello en 1942 como una de la cerámica más representativa que abunda en Wari en proximidad del sector conocido ahora como Cheqo Wasi, identificada como Huari "O" por Rowe, Collier y Willey (1949) y posteriormente estudiado por Bennett (1953) y Lumbreras (1960), corresponde a una variante de Huarpa desarrollada en la época $1 \mathrm{~A}$ y que continúa hasta la época 2 del Horizonte Medio conjuntamente con el estilo Negro Decorado, ambos con formas derivadas de Chakipampa y Robles Moqo, según Menzel (1968). Los fragmentos encontrados se caracterizan por presentar un engobe de color anaranjado tanto en el interior como exterior de las vasijas cuyas formas pertenecen básicamente a cuencos, tazones, jarras, cucharas y estatuillas decorados con diseños de líneas rectas dispuestas de manera horizontal con pequeñas líneas que salen del borde de las vasijas, hay también círculos, franjas y representaciones de la flor y animales marinos. Los fragmentos registrados revelan además imitaciones de formas y diseños copiados tanto de Ocros como de Chakipampa.

\section{Estilo Huamanga}

Definido por Lumbreras (2009), luego estudiado en sus diversas variantes por Benavides (1965), Alarcón (1991), Anders (1998) y Cabrera y OIchatoma (2011a, 2011b). Se trata de una cerámica de pasta roja y anaranjada con engobe también de color rojo y con diseños de líneas rectas, onduladas formando franjas y espacios verticales con divisiones y puntos trazados a manera de alas, y entre una franja y otra rellenados con círculos, semicírculos, aspas, puntos, peines y escalonados, con trazos que parecen estar imitando a diseños o motivos decorativos de la cerámica Huarpa, Viñaque, Ocros, Negro decorado, Chakipampa, Atarco y Cajamarca III trazados con pintura no muy espesa. Cuyas formas características son generalmente escudillas, cuencos, jarras, cantaros, vasos y cucharas. Los fragmentos encontrados en la zona de estudio parecen proceder directamente de Wari o Conchopata.

\section{Estilo Arqalla}

Es una variedad de la cerámica Chanca, definida por Lumbreras (1975) en sus trabajos efectuados en el cerro Arqalla en el distrito de Vinchos, provincia de Huamanga. Se caracteriza por presentar pasta de color anaranjada y rojiza con engobe rojo aplicado como baño al exterior y parte superior interna de las vasijas, que generalmente corresponden a cántaros, ollas, jarras cuencos y escudillas con incisiones continuas en el contorno del cuello o bien con incisiones en pequeñas protuberancias colocadas a manera de adornos e incisiones de líneas en la parte superior externa de cántaros y ollas.

\section{DisCUSIÓN}

No cabe duda que las primeras referencias sobre la presencia y utilidad de cuevas en la ciudad de Wari los da Julio C Tello (1942/2014), luego Lumbreras (1975), quien menciona de la cueva del infiernillo está dividida en varias secciones internas, a manera de cámaras o salones... la cueva seguramente es natural en mayor parte, sin embargo nosotros advertimos...que el interior las paredes parecen trabajadas, pues muestran estrías de manera tal que indican golpes de instrumentos punzantes. Nosotros creemos que fue una cantera de tierra arcillosa. Lumbreras al referirse a las cuevas ocupadas por el hombre desde épocas tempranas menciona que fue Pikimachay siguiendo los estudios de Richard MacNeish de la Robert S. Peabody Foundation. Pero con respecto a los caminos y acueductos no hace referencia alguna.

MacNeish et. al. (1981) quien explora y realizada excavaciones entre 1969 y 1971 en Pikimachay, Ayamachay, Rosamachay, Ruyru Rumy, Puente y en tres abrigos de Tambillo, le corresponde a él 
mérito de haberlo descubierto de manera científica y haber dirigido investigaciones con hallazgos contextuales y distintas áreas de actividad de los primeros pobladores que llegaron a Ayacucho, presentando una cronología absoluta con un fechado temprano y medio ambiente del pleistoceno que oscila entre los 22,000 y 14,000 a.C. aun cuando algunos investigadores no estén de acuerdo con dicha antigüedad aduciendo que los artefactos encontrados son simples desprendimientos del techo o paredes de la cueva.

Referente a los acueductos la encontramos mencionada en la leyenda de los padres rumis o monolitos de Wari escrita por Cabrera (1955), quien hace referencia Hatunsullo el último descendiente que reinó en Wari bajo cuya dirección se construyeron, templos, palacios y la gran acequia llamada Wari-Yarja o el gran acueducto de Pampachacra, así como de la cueva del infiernillo donde fueron encerrados y encontrados los últimos príncipes de Wari cuyas esculturas serian los monolitos que se encuentran en el actual Museo Regional de Ayacucho. Suponemos que por el carácter subjetivo de la versión, nadie lo tomó en cuenta ni mucho menos trató de constatar que en su contenido había algo de objetivo, es el caso del acueducto de Pampachacra y la cueva del infiernillo. Cabe indicar que hasta ahora los acueductos más conocidos y estudiados por la arqueología son los de Nasca y Chimú, sin desmerecer la importancia de otros en los Andes centrales.

En realidad son pocas las referencias sobre caminos (Pérez 1999, 2010; Valdez 2003) lo cual implica la necesidad de ampliar y profundizar los trabajos de prospección en vez de considerarlo quizá como algo no significativo o no espectacular de ahí que en algunas descripciones sobre la ciudad de Wari, (González 1981, 2007; Benavides. 1983; Cabrera. 2005; Ochatoma y Cabrera. 2010), no se hace mención sobre restos de cuevas, canteras y caminos, excepto de lo indicado por Lumbreras; de igual forma Isbell (1972) quien con sus investigaciones en el valle de San Miguel (Jarqampata) Infiere en presencia de caminos que conectan a la metrópoli Wari con el valle del Torobamba o cuenca noreste del pampas, luego Isbell y Schreiber (1978) en base a las exploraciones efectuadas por MacNeish entre 1969 y 1972, señalan que la ciudad de Wari está rodeada de sitios de menor rango y que estos debieron de estar lógicamente enlazados por caminos como parte de una política estatal.

Asimismo podemos señalar que hay muchos sitios arqueológicos cuyas canteras que abastecieron de materiales para la construcción de las edificaciones se encuentran en el mismo lugar como es el caso de los sitios incaicos de Sacsayhuaman, Machu Picchu, etc. o de los sitios Huari de Pikillacta, y Huaro en el mismo Cusco; hay otros sitios cuyos materiales fueron proceden de largas distancias como los bloques líticos del templo del sol en ollantaytambo que fueron traídos desde las canteras de Kachiqhata localizado a $5 \mathrm{~km}$ de distancia y entre 400 y $900 \mathrm{~m}$ sobre el nivel del valle Urubamba ( Pierre 2005), así como la procedencia y transporte de bloques lítico de Tiwanaku que según Ponce (2004) fueron traídos desde más de $10 \mathrm{~km}$ de distancia utilizando la participación de numerosos trabajadores con la técnica del rodado mediante madera y cantos rodados. En el caso de la ciudad de Huari tanto las piedras pequeñas como los grandes bloques megalíticos proceden de varios sectores de la misma ciudad: Canterón, San Cristóbal, Cercaduqoq, Ayamonte, Zapalloqasa, Torresmoqo, Wallpaqasa, Trancaqasa, etc.

\section{Conclusiones}

De los 34 restos arqueológicos reconocidos en la ciudad de Wari y alrededores 11 pertenecen a la categoría de canteras, 5 a cuevas, 01 acueducto y 17 caminos.

La cantera del infiernillo contiene arcilla arenosa como la que se utilizada como mordiente para mezclar con arcilla plástica para la elaboración de cerámica, y Curiorqo fue la cantera de donde se 
obtenía arcilla para impermeabilizar el piso del canal mientras que Jayhuacanche, Nueva esperanza, Sulluhuasi Wayqo y Checclla wayqo son lugares de donde se obtenía arcilla pura la elaboración de cerámica.

De Yanacocha se obtenía parte de la piedra utilizada en el canal de Inkapa Yarccan a Wari Yarccan; mientras que de Wallpaqasa, Ayamonte, Zapalloqasa y Torrespamoqo la piedra para la construcción de los distintos componentes arquitectónicos de la ciudad de Wari.

El acueducto o mampuesto de Pampachacra es único en la serie de ingeniería hidráulica en el valle de Ayacucho el cual fue tomado como modelo para la construcción de otros canales de la época Wari en los andes centrales.

Los 17 restos de caminos corresponden a diferentes tramos de caminos que unen a la ciudad de Wari con poblados aledaños, destacando el camino de Chiwa el cual es empedrado con parapetos, graderías, descansos, puentes y drenajes. La mayoría de los caminos son de la época Wari, pero hay algunos más tempranos dela época Huarpa o quizá del periodo Formativo.

\title{
RECONOCIMIENTO
}

En esta oportunidad hacemos llegar nuestro reconocimiento a Angélica Canchari Castro y Alexander Salvatierra Chavarría por su apoyo en el trabajo de campo como parte del Plan de Manejo del complejo arqueológico Wari dirigido por Luis G Lumbreras, de igual manera a Noemí Cruz Azahuanche por su apoyo en labores de gabinete.

\section{REFERENCIAS BibLIOGRÁFICAS}

\author{
ANDERS, Martha
}

1998 “El Estilo Wamanga: Resistencia y Subversión simbólica manifestadas en la cerámica del Horizonte Medio 2". Conchopata Revista de Arqueología 1:138-162.Oficina de Investigación, Facultad de Ciencias Sociales, Universidad Nacional de San Cristóbal de Huamanga.

ALARCON, Marleni

1991 Los olleros de Aqo Wayqo. Informe de práctica pre profesional. Facultad de Ciencias Sociales, Universidad Nacional de San Cristóbal de Huamanga, Ayacucho.

BENNETT, Wendell

1953 Excavations at Wari, Ayacucho, Perú. Yale University Publications in Antropology 49.

BENAVIDES, Mario

1965 “Análisis de la cerámica Huarpa”. Revista del Museo Nacional Vol. XXXVII: 63-88, Lima.

1983 Carácter del Estado Wari. Universidad Nacional de San Cristóbal de Huamanga.

CABRERA, Néstor

1955 "Los padres rumis o monolitos de Wari". Anuario del Museo Histórico Regional de Ayacucho. Año 3 №3 2829, Ayacucho.

CAVERO, Luis

1953 Monografía de la Provincia de Huanta, Tomo I, Lima. 
CABRERA, Martha

Ms.1998. “Evaluación arqueológica en el complejo turístico de Ñawimpuquio”. Informe presentado al Instituto Nacional de Cultura.

2005 "Sociedad y estructura del espacio urbano en Wari-Ayacucho". Itinerarios del proceso urbano: Ayacucho en la perspectiva de la Antropología urbana, Escuela de Pos Grado de la Universidad Nacional de San Cristóbal de Huamanga. Pp. 21-40. Primera edición, Huancayo Perú.

CABRERA, Martha y OCHATOMA, José

2011a “El estilo Huamanga: Formas e iconografía en la cerámica doméstica durante el imperio Huari”. Revistra Cobchopata N 3: 167-228. Ismael Pérez (editor), Facultad de Ciencias Sociales, Universidad Nacional de San Cristóbal de Huamanga.

CRIADO, Felipe

1999 Del terreno al espacio: planteamientos y perspectivas para la Arqueología del Paisaje. Criterios y Convenciones en Arqueología del Paisaje Nº. Grupo de Investigación en Arqueología del Paisaje, Universidad de Santiago de Compostela, España.

GAGLIARDI, Roberto

2013 "Notas sobre la estructura del cerro Corpas, Ayacucho". Boletín de Lima N 171:8-12 (Rogger Ravines/editor) Editorial Los Pinos, Lima.

GONZALEZ, Enrique

1981 “La antigua ciudad de Wari en Ayacucho". Boletín de Lima. Números 16-17-18: 83-97 Editorial Gráfica Pacific Press, Lima.

2007 Historia prehispánica de Ayacucho. Lluvia Editores, Lima.

GONZÁLEZ, Enrique y CAHUAS, José

1984 El sitio arqueológico de Kumunsenqa. Dirección Universitario de Investigaciones, Universidad Nacional de San Cristóbal de Huamanga.

ISBELL, William $\mathrm{H}$.

1972 "Huari y los orígenes del primer imperio andino". Pueblos y Culturas de la sierra Central del Perú. Cerro de Pasco, Corporación, Lima Perú, pp. 52-65

ISBELL, William H. y SCHEREIBER, Katharina

1978 “Was wari a state”. Américan Antiquity, 43(3):372-389, Washigton D.C

LUMBRERAS, Luis

1959 “Sobre los Chankas”. Actas del II Congreso Nacional de Historia del Perú. Tomo I. 211-242. Lima.

1960 “La Cultura Wari, Ayacucho". Revista Etnología y Arqueología, Publicación del Instituto de Etnología y Arqueología, Universidad Nacional Mayor de San Marcos, año I № I mayo, pp.130227. Lima. 155 
1969 De los pueblos las culturas y las artes del Antiguo Perú. Moncloa Campodónico- Editores Asociados.

1975 Las Fundaciones de Huamanga. Hacia una Prehistoria de Ayacucho. Editorial Nueva Educación. Lima.

LEONI, Juan

2009 Archeologycal investigations at Ñawimpuquio Change and continuity in an early intermediate period and middle horizon community in Ayacucho, Perú.BAR International Series 1991. Printed in England

KNOBLOCH, Patricia

1991 "Stylistic Date of Ceramics fron the Huari Centers". Huari Administrative structure, Prehistoric Monumental Architecture and State Gpvernment. Eilliam H. Isbell and Gordon F. MacEwan, Editores. Pp.247-258. Dumbarton Oaks research Library and Colecctión Washigton, D.C.

MAC NEISH, Richard; GARCÍA, Ángel; Luis LUMBRERAS, Luis; VIERRA, Robert y NELKEN-TERNER, Antoinette.

1981. Prehistory of the Ayacucho Basin, Perú. Volumen II. Excavations and Chronology. Ann Arbor, The University Of Michigan Press.

MENZEL, Dorothy.

1968 La Cultura Huari. Compañía de petróleos peruano suizo.

OCHATOMA, José y CABRERA, Martha

2010 “Los espacios de poder y el culto de los ancestros en el imperio Huari”. Los imperios del Sol. Pp. 130-142. Edición Banco de Crédito del Perú.

OCHATOMA, Pavel

2011 La agricultura Huarpa en el valle de San Miguel: Una visión a partir de los andenes de Uras. Tesis para optar el título de Licenciado en Arqueología, Facultad de Ciencias Sociales, Universidad Nacional de San Cristóbal de Huamanga, Ayacucho

PÉREZ, Ismael.

1999 Huari: Misteriosa ciudad de piedra, Ayacucho, Universidad Nacional de San Cristóbal de Huamanga.

2005, Investigación y evaluación arqueológica del canal prehispánico de Inca Yarccan, Ayacucho. Informe Final presentado al INC.

2009 Asentamientos periféricos en la ciudad de Wari. Informe para el Plan de manejo y Uso Turístico del complejo arqueológico Wari, elaborado por el Dr. Luis lumbreras para el gobierno regional Ayacucho.

2010 "Wari: estructura urbana y funcionamiento de la ciudad imperial". Resúmenes IV Simposio Nacional de Arte Rupestre Pp. 98-107. Universidad Nacional de San Cristóbal de Huamanga. 
PÉREZ, Ismael y AQUINO, Nelson

2016 “La ocupación Huarpa en el Valle de Tambo, La Mar”. Arqueología y Sociedad №30:257-258. Museo de Arqueología y Antropología de la Universidad Nacional Mayor de San Marcos.

PIERRE, Jean

2005 Arquitectura y construcción incas en Ollantaytambo. Pontificia Universidad Católica del Perú, Fondo Editorial.

PONCE, Carlos

2004 Tiwanaku y su fascinante desarrollo cultural, Ensayo de síntesis arqueológica Tomo II estudio sobre la economía y tecnología en Tiwanaku prehispánico. Producciones "CIMIA" La Paz- Bolivia.

RUIZ, José

1924 Monografía Histórico Geográfico del departamento de Ayacucho. Imprenta Torres Aguirre, Lima.

ROWE, Jhon, COLLIER, Donald y WILLEY, Gordon.

1949 “Reconnaisance notes on the Site of Huari near Ayacucho, Perú". Américan Antíquity 16:120-137. Washington D.C.

SALAZAR, Rodolfo

1936 "Ruinas inkas de Yanaccocha". Huamanga. Año I N 6: 42-45, Órgano del Centro cultural de Ayacucho.

TELLO, Julio

1942 (2014) Cuadernos de Investigación del Archivo Tello Nº 12. Expedición al Vilcabamba, 1942 Primera Parte: Sierra Central y Cusco. Museo de Arqueología y Antropología, Universidad Nacional Mayor de San Marcos.

VALDEZ, Ernesto

2003 "El camino prehispánico que une a los valles de Huamanga y Huanta". Cuadernos de Arqueología Pp. 3-4. Universidad Nacional Mayor de san Marcos.

VALDEZ, Lidio y VALDEZ, Ernesto

1998 “Inkapayarqan: un canal en la puna de Ayacucho". Boletín del Museo de Arqueología y Antropología, Universidad Nacional Mayor de San Marcos.

2005 “Pueblos del Intermedio tardío”. Revista Arqueológica Warpa № 3:27, Huanta, Ayacucho. 